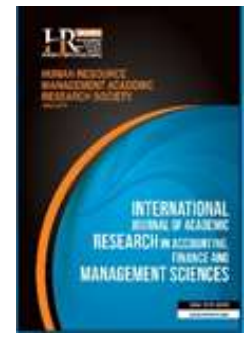

International Journal of Academic Research in Accounting, Finance and Management Sciences

Vol. 9, No.4, October 2019, pp. 207-217

E-ISSN: 2225-8329, P-ISSN: 2308-0337

(C) 2019 HRMARS

www.hrmars.com

To cite this article: kh El-Dalabeeh, A.-R., AIZughoul, M.S. (2019). The Impact of Expert Systems on Enhancing the General Controls over the Computerized Accounting Information Systems, International Journal of Academic Research in Accounting, Finance and Management Sciences 9 (4): 207-217

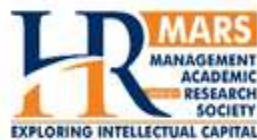

\title{
The Impact of Expert Systems on Enhancing the General Controls over the Computerized Accounting Information Systems
}

\author{
Abdel-Rahman kh. El-Dalabeeh ${ }^{1}$, Mohammed Said AlZughoul ${ }^{2}$ \\ ${ }^{1,2}$ Department of Accounting, Faculty of Economics and Administrative Sciences, Al al-Bayt University, Jordan, \\ E-mail: dalabih@aabu.edu.jo (Corresponding author)
}

\begin{abstract}
This study aimed to identify the impact of expert systems in improving the general controls of computerized accounting information systems in the Jordanian industrial public shareholding companies listed in Amman Stock Exchange. To achieve this goal, the researchers depended on the descriptive and analytical approaches. The study population consisted of all Jordanian industrial public shareholding companies and the study sample was selected from companies using the expert systems, numbering 32 companies. A questionnaire was formulated and 140 copies were distributed. SPSS was used to analyze data. The researchers found that there is an impact of expert systems in improving the general controls of the computerized accounting information systems four pillars, regulatory controls, access controls, controls the security of files, and documentation of controls and the development and maintenance of devices. Based on the result, the researchers recommended that there is a need of developing training programs for the staff of the Jordanian industrial companies to increase their awareness and understanding of the uses of expert systems, as this could assist them in avoiding errors during system use and consequently lead to strengthening general controls in the companies.

Key words Expert Systems, General Controls, Accounting Information Systems, Computerized Ais, Industrial Jordanian Companies

\begin{tabular}{|c|c|c|}
\hline Received: & 17 Jan 2020 & (C) The Authors 2019 \\
\hline Revised: & 23 Jan 2020 & Published by Human Resource Management Academic Research Society (www.hrmars.com) \\
\hline Accepted: & 26 Jan 2020 & This article is published under the Creative Commons Attribution (CC BY 4.0) license. Anyone may \\
\hline ed Online: & 10 Feb 2020 & $\begin{array}{l}\text { reproduce, distribute, translate and create derivative works of this article (for both commercial and } \\
\text { non-commercial purposes), subject to full attribution to the original publication and authors. The full } \\
\text { terms of this license may be seen at: } h \text { ttp://creativecommons.org/licences/by/4.0/legalcode }\end{array}$ \\
\hline
\end{tabular}
\end{abstract}

\section{Introduction}

Factors, such as, diversity of commercial projects goals, the variability of its internal and external branches, the emergence of the multinational companies and the spread of electronic commerce, have increased the need for suitable accounting information for planning, controlling and decision making (Jawabreh and Alrabei, 2012) to guarantee the existence and sustainability of companies (Braam and Peeters 2018). Hence, the need for what is called artificial intelligence has been identified and it is considered as one of the major types of information systems from which the expert systems are generated (Issa et al., 2016). The expert systems are considered as one of the most successful and applicable systems of artificial intelligence (Bahrammirzaee, 2010), representing the entire growth of the accounting information. It is characterized as one of the developed applications that help in achieving effective control over the accounting information through enhancing the system's general auditing controls (organizational controls, controls of access to programs and systems, controls of developing and maintaining the systems) (Hall 2011). As all of these controls represent the basic components of the effective auditing controls, it 
becomes a necessity to study the impact of these systems on controls activation. Despite the fact that Jordan is a developing country, it keeps up with technologies in the sector of industrial public shareholding companies that have a great role in promoting the domestic product, decreasing the unemployment rate, and supporting the country's budget by income tax. Accordingly, the industrial companies sector was chosen as the population of the study.

\section{Problem Statement}

Requirements of electronic business environment, which are based on information technology and its implementation in organizations (El-dalabeeh, 2019), have caused accounting and auditing procedures to be required to develop programs to cope with the technological and technical development. And because the industrial shareholding companies care greatly about the application of developed and advanced systems and the complexity of production operations, the management of raw materials and its availability, need for marketing goods and managing company resources, all necessitated the adoption of artificial intelligence systems as expert systems (Mehrabad and Brojeny, 2007)and its vital role in companies different operation that simulate the human mind and actions (Cheng et al., 2018). Accordingly, the determination of the way the above variables can be met involves the examination of auditing control systems in companies and the identification of the extent to which the systems are affected by expert systems and this is summarize of this study contribution, so The study problem can be summarized in the following main question and sub-questions:

Is there an impact of expert systems on enhancing the general control audits of the electronic accounting information systems in the Jordanian industrial companies?

1. Is there an impact of expert systems on enhancing the regulatory controls?

2. Is there an impact of expert systems on enhancing the access?

3. Is there an impact of expert systems on enhancing the files security controls?

4. Is there an impact of the expert systems on enhancing the controls of system development and maintenance?

\section{Study importance and Goals}

The significance of this study lies in addressing the expert systems and highlighting their impact on enhancing the general control audits of the electronic accounting information systems. The study seeks to show the relationship between those two variables, which hopefully would contribute to a new dimension to the field of enhancing the effectiveness of Accounting Information System (AIS). Ultimately, this will help organizations to acquire the necessary knowledge and reconstruct it to achieve success and be able to compete for its ability to store information in database stimulating the decision-making process of experts. The following are the main aspects that show the importance of this study and its goals;

1. To recognize the significance, advantages and impact of the expert systems on helping managers and decision makers to execute their business rapidly and accurately to solve the problems they encounter at work;

2. To identify the concept of the control audits of the accounting information systems and its four components; the regulatory controls, access controls, files security controls, controls of system development and maintenance; and

3. To explain the relationship between the expert systems and the general control audits of these systems.

\section{Literature Review}

The expert systems are one of the latest production of the information systems through using artificial intelligence (Leigh et al., 2002), and they constitute one of the types of accounting information systems that aim to design and develop systems that simulate human intelligence, in an attempt to use artificial intelligence to solve problems and take various decisions. Moreover, expert systems aim to give the machines the ability to carry out intelligent processes, which are done by humans (Widodo and Yang, 2007). 
Expert systems can be defined as "one of the artificial intelligence branches that work on emerging the knowledge and solving problems' skills to simulate the human expert's skills in taking strategic decisions for solving problems". In addition, these systems deal with the situations in which there is "no certainty of deduction and logical reasoning" (Moscove et al., 2001). It is also defined as a combination of intellectual understanding of a problem and the compilation of bases to solve the problem in an efficient manner. The expert systems are based on obtaining knowledge from the human expert and constructing it in a way that is possible to be implemented on a computer to tackle similar issues (Chandrasekaran, 1986). These expert systems are computer programs that are specialized in giving advice, analysis, categorization, communication, consultation, design, prognosis, clarification, exploration, prediction, regulation, knowledge, management, control, planning, instructing and testing (Price and Price 1999). The researchers believe that the expert systems are easy to use by specialists and non-specialists in the computer. In addition, these systems are flexible and can be modified to conform to the surrounding environment. Moreover, these systems can work depending on uncertain information and they can transmit knowledge from one place to another. Yang and Vasarhely (1995) believed that the expert systems;

1. Have the ability to deal successfully with uncertain situations of programmed or unstructured tasks or work.

2. Help to take different decisions in terms of explaining the solution of the problem efficiently and effectively.

3. Can provide fast and developed services in all fields; it can be categorized into the following main types (Hazratzadeh and Navimipour, 2016):

- Assistant systems: A system which help the user to perform the routine analysis for some work.

- Collage Systems: A system that depends on queries to understand the logic that the system uses in order to reach for a common decision if the process was correct. However, if the process was wrong, the system will be corrected by providing more information to it.

- True Expert: A system qualified to be equal to the highest cognitive and intelligent level of human intellect; it can perform the tasks that only highly experienced experts can.

Many fields have implemented the expert systems successfully to contribute scientific and practical excellence such as, in business administration, where workers are assisted in a certain work and authenticity confirmation, such as, accounting reports and the financial lists (Al-Qumboz, 2019; Thaker and Nagori, 2018). Using the expert systems technique is considered to be a sign of development of the auditing profession in general, and it helps auditors to perform tasks rapidly at a suitable time. In addition, their skills can be improved and developed to acquire further experience. Due to the great significance of the expert systems, professional bodies and organizations have encouraged their implementation in the fields of accounting and auditing. In a published report by The American Institute of Certified Public Accountants (AICPA), using the expert systems in the fields of control and auditing accounts can give the following advantages:

1. The expert systems increase the productivity of workers in the offices of auditing, rapidly and accurately. The workers' ability to process complex analysis is increased (Lee et al., 2011).

2. The expert systems give an opportunity to create a deep understanding of knowledge, which will help the audit expert to reconsider their practice in a conscious and in-depth manner. Moreover, these systems help beginners to acquire knowledge and use them in training programs, as well as, a control tool for quality (McDuffie and Murphy 2006).

\subsection{The general controls over computerized AIS}

The information systems, which are used inside the organization, can be divided to serve the administrative levels into the following sections (Lutui and Ahokovi, 2018; Widodo and Yang, 2007; Ahmad, 2019; Bawaneh, 2018);

- Database Management Systems: The systems which process data inside the computer and produce reports to support the various operational systems.

- Management Information Systems: A series of organized processes that use the various administrative levels to obtain the necessary information for executing tasks and taking decisions. 
- The Decision Support Systems: The job of these systems is to support administrative body in taking decisions, which is one of the main administrative tasks.

- The Artificial Intelligence Systems: The systems which work on designing and developing computerized systems that simulate the human intelligence and use the artificial intelligence systems to solve problems and take various decisions.

- The Expert Systems: One of the artificial intelligence branches that work on merging the knowledge and skills of solving problems like the way of human experts, and dealing with solving problems, which require theoretical knowledge and practical experience. Here, the science expert and the computer expert meet to design an accounting system that is characterized by intelligence and ability to solve problems encountered by the business owners in executing tasks. It also helps in acquiring the necessary knowledge and reconstructing it for competition. In addition, it assists the organization to achieve success and gain a good long-term competitive space (Chandrasekaran, 1986).

The general control audits of the accounting information systems include the following four elements that represent the major controls; the regulatory controls, the access controls, files security controls and the controls of system development and maintenance (SAS No.3 AICPA, 1974). Considering the great significance of these controls, it is necessary to explain and define their concepts and functions, which are as follows (Appiah et al., 2017):

The regulatory control: This represents the holistic audits and control procedures of the whole organization. These controls pay attention to the regulatory structure of the institution in terms of jobs description, division between the sections and the information systems management by identifying responsibilities for each part within the computer department itself. These controls can include job rotation and employees; for instance, vacation leaves to build expertise and to be used as work guidance, and this is what the third edition of audit have indicated (SAS No. 3). Thus, the tasks of programmers and accountants should be separated (Romeny, 2006)

The access controls: These controls include the control procedures that inhibit the access of the unauthorized computers and system data, in addition to identifying the scope that is compatible with nature and load of their work to prohibit fraud and the unauthorized use of the machines and the programs. The logical access and the control audits on this type of access include the designed procedures that aim to control the access into the logical components of the system (Romeny, 2006).

File security controls: These controls secure and protect the system components including both the physical and logical types. Moreover, these controls face various risks such as, the unauthorized access risks to the hardware and the programs. In addition, they secure the system from natural external factors that might cause great damage to the system and its programs (Stantchev et al., 2014).

Controls of system development and maintenance of system: The aim of these controls is to document, develop and maintain the information systems and their logical and physical components, which are rectified and described. They also document the procedures of the end user who uses the system. Moreover, all of the development and constant modifications of systems during and after the operation of system are documented.

\subsection{Previous Studies}

Many studies have spotted the light on the emergence of the expert systems in the fields of accounting, particularly in management and planning (Issa and Vasarhelyi, 2016; Yang and Vasarhely, 1995; Qin et al., 2008). These studies examined the use of the expert systems in auditing, taxing and financial accounting, and reached to the conclusion that expert systems are branches of the accounting information systems and they are necessary for the success of planning and practicing of the economic and managerial fields, especially the field of accounting. To begin with this line of study, Flowerday and Von Solms (2005) confirmed the value of the expert systems as an asset for the auditing reports, especially for the (ADVPORT); an expert system for auditing reports. As for the study by Beard and Wen (2007), it identified the threats that are encountered in electronic accounting information systems and information security. In addition, the study also highlighted the relationship between the different levels of threats and the power level of management as well as the degree of information security. The study concluded that implementing 
a suitable level of control audits that guarantees the production of validated financial information is the company management's role.

Also, Devale and Kulkarni (2012) aimed to reveal the role of the groundbreaking techniques in the field of auditing, which allows auditors to identify risks and to assess the efficiency of control on the modern information systems. Moreover, the study assured that although auditing techniques of computer programs, such as expert systems, could be used to enhance the work procedures and minimize mistakes, it is still in the primary stages of development. The study also pointed that companies should secure procedures related to computerized accounting information applications.

Moreover, Omoteso (2012) and Barta (2018) examined the use of artificial intelligence in the procedures of auditing in light of auditing and audit standards. They showed that auditing procedures require development in the environment of modern business and auditors should increase their efforts to have an effective role in judgment and control. They reached to the conclusion that the necessary procedures to develop the expert systems, which are used in auditing, increase the efficiency of auditing and decrease the shortcomings that might limit auditing in the light of the expert systems. Moreover, they discussed the importance of using artificial intelligence in the internal control evaluation by auditors, the benefits of adopting these systems in auditing and the impact of artificial intelligence on designing the internal control systems through suggestions that can be used in the future (Baldwin et al., 2006).

Furthermore, Kozhakhmet et al. (2012) assured the high expense of implementing the expert systems in companies in terms of time and the human resources. The automation of the auditing process using the development programs can be a good alternative for decreasing expenses (Chan and Vasarhelyi, 2011), accelerating the auditing process and improving quality by complying with the international auditing standards. Simin et al. (2013) conducted a study aimed at explaining the overall concept for the impact of the expert systems and their applications on the performance of managers in business organizations. The study found that the importance of the expert systems generated from the computerized accounting information systems have increased as a result of increasing need of all organizations to take decisions and obtain fast, accurate and rational costly solutions for ambiguous and complicated cases. This was similar to other prior studies (El-Dalabeeh and Al-Shbiel 2012; Al-Dalabeeh and Al-Zeaud 2012).

Finally, the study of (Aboa, 2014; Prajogo, 2016) focused on the role of modern technology in the business environment and considered it as a factor that causes changes in the field of continuous auditing. It also aimed at assessing whether accounting or auditing can show creativity and brilliance continuously in operation processing and determine the necessary solutions for problems that might be encountered as a result for implementing the technological advancement in institutions. The study concluded that continuous auditing procedures are necessary for implementing technology in the business environment but at the same, there are some obstacles that accompany this type of implementation and hinder the work of accounting and auditing. In order to overcome these obstacles, the date of auditing should be revised and its relation to the information technology and the necessary procedures for this development should be identified.

\section{Methodology of Research and Data Analysis}

In this field of study, the researchers depended on the descriptive and analytical methods by presenting the concept of expert systems and general control audits through reviewing literature and addressing the previous studies and periodicals.

\subsection{Study Population and Sample}

The study's population consisted of all the Jordanian industrial public shareholding companies listed in the stock market of Amman, Jordan. The unit of analysis, which contributed to the questionnaire completion, consisted of all of the chief financial officers, accountants, internal auditors and programmers, who work in the Jordanian industrial companies that use the expert systems (32 companies representing $(48,4 \%)$ of the industrial companies). As for the employees of finance department, they were represented by the chief financial officer, heads of departments and accountants. The employees of the internal auditing department were represented by the internal auditing manager, heads of internal auditing departments, internal auditors. While the (129) employees of the computer department and the 
information systems were represented by analysts and programmers in the companies that use expert systems-employees who were aware of its use in accounting and auditing.

\subsection{Data Collection}

After reviewing the prior theoretical literature concerning the expert systems, a questionnaire was prepared to examine the impact of the expert systems on enhancing the general control audits of the electronic accounting information systems. The answers of the questionnaire copies were ranked on a 5point Likert scale (strongly disagrees 1 to strongly agree 5 ), divided into the following fields:

The first field included the following statements; Enhancing the process of separation between the management of information systems and other managements, rotating jobs between employees to gain expertise and various skills inside the systems department, reinforcing the process of qualifying the appropriate and necessary staff to manage the accounting information systems, separating between programmers, accountants and system analysts and defining their authorities, organizing and coordinating vacation leaves of the accounting information systems department, setting an operation operations manual to describe jobs and tasks for each user, reinforcing the separation between the jobs and tasks of finance department employees, and reinforcing the separation between the jobs and tasks inside the management of information systems.

The second field included the following statements: Giving access to the computers room and systems department only to those who are authorized, using a password to access computers and tabulating data based on importance and sensitivity, giving a password for each employee in the systems department and computer room, using security cameras to control the access to the computers room and systems department, using alarms to control the unauthorized physical access to computers room, using the employee's ID card (Magnetic Card) to control the physical access (the person) to the computers room, using the Visitors Log Book to sign when entering or exiting from the management of systems, using firewalls technique to control access and using the SMS Notification.

The third field covered the following statements: Using developed and adequate programs to protect computers and software from viruses, giving the responsibility of saving files and programs to qualified people, keeping backup versions in a safe place out of reach and operating sites, creating a guide for programs and important files, making periodical tests and using pilot operation in the alternative sites to check readiness, protecting files using the three generation technique (son-father- grandfather) for backups, designing a plan for disaster management by making a contract with the supplier to provide the company with the operation sites, and using the main ID card and the back of the card to identify the stored data in storage media.

The fourth field included the following statements: reinforce creating a guide that includes a specific description for authenticating programs and equipment used in system, reinforce setting a clear plan for developing and maintaining systems and programs that include goal setting, reinforce participation in developing system by users, reinforce documenting the adjustments made on programs, computers and equipment, reinforce designing a written guide to document the automation software, reinforce documenting errors that happen in the system in the error log and conducting review of this log periodically, create a documentation guide that includes a descriptive outline for each job in terms of (inputs, processes and outputs).

\subsection{Validity and Reliability of Instrument}

The researchers designed the questionnaire based on the literature reviews concerning the expert systems and the general control audits. The degree of reliability of the study's instrument was tested using Cronbach's Alpha, as illustrated in Table 1. It is noted from the table that all of the items of alpha values $(\alpha)$ are higher than the acceptable percentage (75\%), which assures the reliability of the instrument and represents the acceptable percentage of the internal consistency 
Table 1. Cronbach's alpha value for the internal consistency of study variables and analysis purposes

\begin{tabular}{c|c|c}
\hline Items & Name of item & Cronbach's alpha \\
\hline $1-8$ & Regulatory controls & $81 \%$ \\
\hline $9-17$ & Access controls & $88 \%$ \\
\hline $18-25$ & Files security controls & $86 \%$ \\
\hline $33-36$ & Hardware development and maintenance controls & $85 \%$ \\
\hline $1-33$ & Overall reliability percentage & $84 \%$ \\
\hline
\end{tabular}

Source: Prepared by researchers using SPSS

Data and the necessary information concerning the study's variables were collected and analyzed statistically using Statistical Package for the Social Sciences (SPSS).

\section{Results' Analysis}

Results concerning the first sub-hypothesis: "There is no impact of expert systems on enhancing the regulatory controls of the computerized accounting information system in the Jordanian industrial companies". To check this hypothesis, means and standard deviations of the respondents' answers were calculated in addition to the application of One Sample T-test as illustrated in Table 2.

Table 2. Results of One Sample T-test

\begin{tabular}{|c|c|c|c|c|c|c|c|}
\hline Hypothesis & $M$ & STD & Value & $T$ & df & SIG. & Result \\
\hline $\begin{array}{l}\text { "There is no impact of expert systems on enhancing } \\
\text { the regulatory controls of the computerized } \\
\text { accounting information system in the Jordanian } \\
\text { industrial companies" }\end{array}$ & 4.22 & 0.51 & High & 27.355 & 128 & 0.00 & $\begin{array}{l}\text { Rejection of } \\
\text { hypothesis }\end{array}$ \\
\hline
\end{tabular}

Source: Prepared by researchers using SPSS tabulated T(1.96) *

Table 2 showed effect of the expert systems in enhancing the organizational control, restricting the electronic accounting information systems in the Jordanian industrial companies. T value (27.355) was considered significant at $(\alpha \leq 0.05)$ and the standard deviation was (0.51). The mean of the respondents' answers concerning the hypothesis of "the impact of the experts systems in enhancing the regulatory controls of the Computerized accounting information system" was higher than the standard score, which indicated a significant impact at the $(\alpha \leq 0.05)$. This result concurs with the study of Devale and Kulkarni (2012), which found that auditing techniques of computer programs, such as expert systems, could be used to enhance the work procedures and minimize errors in the primary stages of development. Moreover, most researches sought to look for the security and auditing procedures that should accompany the applications of the computerized accounting information system in companies.

Results concerning the second sub-hypothesis: "There is no impact of expert system on enhancing the access controls in the Jordanian industrial companies".

To check this hypothesis, means and standard deviations or the respondents' answers were calculated in addition to the application of One Sample T-test as illustrated in Table 3.

Table 3. Results of One Sample T-test

\begin{tabular}{c|c|c|c|c|c|c|c}
\hline Hypothesis & $\mathbf{M}$ & Std & Value & T & df & Sig. & Results \\
\hline $\begin{array}{l}\text { "There is no impact of expert system } \\
\begin{array}{l}\text { on enhancing the access controls in } \\
\text { the Jordanian industrial companies" }\end{array}\end{array}$ & 4.27 & 0.63 & High & 22.67 & 128 & 0.00 & $\begin{array}{c}\text { Rejection of } \\
\text { hypothesis }\end{array}$ \\
\hline
\end{tabular}

Source: Prepared by researchers using SPSS tabulated T(1.96) *

Table 3 shows that there is effect of the expert systems in enhancing the access controls in the Jordanian industrial companies. T value which was (22.67) was considered significant at $(\alpha \leq 0.05)$ and the standard deviation was (3). The mean of the respondents' answers concerning the hypothesis of "the impact of the experts systems in enhancing the access controls in the Jordanian industrial companies" was higher than standard score to a high degree, which indicated a significant impact at the $(\alpha \leq 0.05)$. Accordingly, the hypothesis is rejected.

Results concerning the third sub-hypothesis: "There is no impact of expert systems on enhancing the security and protection of information in the Jordanian industrial companies". To check this hypothesis, 
means and standard deviations or the respondents' answers were calculated in addition to the application of One Sample T-test as illustrated in Table 4.

Table 4. Results of One Sample T-test

\begin{tabular}{l|c|c|c|c|c|c|c}
\hline Hypothesis & $\mathbf{M}$ & Std & Value & T & df & Sig. & Result \\
\hline $\begin{array}{l}\text { "There is no impact of expert systems on } \\
\text { enhancing the security and protection of } \\
\text { information in the Jordanian industrial } \\
\text { companies" }\end{array}$ & 4.34 & 0.54 & High & 28.53 & 128 & 0.00 & $\begin{array}{c}\text { Rejection of } \\
\text { hypothesis }\end{array}$ \\
\hline
\end{tabular}

Source: Prepared by researchers using SPSS tabulated T(1.96)*

Table 4 shows the presence of effect of expert systems on enhancing the security and protection of the information in the Jordanian industrial companies. T value (28.53) was considered significant at $(\alpha \leq 0.05)$ and the standard score was (3). The mean of the respondents' answers concerning the hypothesis of "the impact of expert systems on enhancing the security and protection of the information in the Jordanian industrial companies" was higher than the standard score to a high degree, which indicated a significant impact at the ( $\alpha \leq 0.05)$. Therefore, the hypothesis was rejected.

Results concerning the fourth sub-hypothesis: "There is no impact of the expert systems on enhancing the controls of hardware documentation development and maintenance in the Jordanian industrial companies". To check this hypothesis, means and standard deviations or the respondents' answers were calculated in addition to the application of One Sample T-test as illustrated in Table 5.

Table 5. Results of One SampleT-test

\begin{tabular}{l|l|l|l|l|l|l|l}
\hline Hypothesis & $\mathbf{M}$ & Std & Value & T & df & Sig. & Result \\
\hline $\begin{array}{l}\text { "There is no impact of the expert systems on } \\
\text { enhancing the controls of hardware } \\
\begin{array}{l}\text { documentation development and } \\
\text { maintenance in the Jordanian industrial } \\
\text { companies" }\end{array}\end{array}$ & 4.00 & 0.56 & High & 20.08 & 128 & 0.00 & $\begin{array}{c}\text { Rejection of } \\
\text { Hypothesis }\end{array}$ \\
\hline
\end{tabular}

Source: Prepared by researchers using SPSS tabulated T(1.96)*

According to Table 5, there is an impact of the expert systems on enhancing the controls of hardware documentation development and maintenance in the Jordanian industrial companies. T value (20.08) was considered significant at $(\alpha \leq 0.05)$ and the standard score was (3). The mean of the respondents' answers concerning the hypothesis, "the impact of the expert systems on enhancing the controls of hardware documentation development and maintenance" was higher than the standard score, with a high rate, which indicated a significant impact at the $(\alpha \leq 0.05)$. Therefore, the hypothesis was rejected.

To check the validity of the main hypothesis, T-test was implemented on the questionnaire as a whole, as illustrated in Table 6.

Table 6. Results of T-Test

\begin{tabular}{l|c|c|c|c|c|c|c}
\hline \multicolumn{1}{c}{ Hypothesis } & $\mathbf{M}$ & Std & Value & T & df & Sig. & Result \\
\hline $\begin{array}{l}\text { "There is no impact of the expert systems on } \\
\text { enhancing the general control audits of the accounting } \\
\text { information systems" }\end{array}$ & 4.21 & 0.46 & High & 29.63 & 128 & 0.00 & $\begin{array}{c}\text { Rejecting the } \\
\text { hypothesis }\end{array}$ \\
\hline
\end{tabular}

Results of implementing One Sample T-test on the data collection tool as a whole

Source: Prepared by researchers using SPSS tabulated T(1.96)*

According to Table 6, there is an impact of the expert systems on enhancing the general control audits of the electronic accounting information systems in Jordanian industrial companies. T value (29.63) was considered significant at $(\alpha \leq 0.05)$ and the standard score was (3). The mean of the respondents' answers concerning the hypothesis, "there is an impact of the expert systems on enhancing the general control audits of the electronic accounting information systems in Jordanian industrial companies" was higher than the standard score, with a high rate, which indicated a significant impact at the $(\alpha \leq 0.05)$ and as such, the hypothesis was rejected. 


\section{Conclusions}

After analyzing the data and testing the hypotheses, the results of the study can be summed up as follows;

There is an impact of expert systems on enhancing the general control audits of the electronic accounting information systems in the Jordanian industrial companies listed in the stock market of Amman;

1) There is an impact of the expert systems on enhancing the regulatory controls of the electronic accounting information systems in the Jordanian industrial companies by taking into account the enhancement of separating between jobs and duties inside the management of information systems. This indicates that the expert systems have high potential for controlling the organization processes after identifying the standards of any failure or bypassing what happens in any of the organization processes. This is possible through continuous planning of the life cycle of the electronic accounting information systems, used primarily to address and resolve threats that could be encountered by its security.

2) There is an impact of the expert systems on enhancing the access controls in the Jordanian industrial companies by allowing authorized personnel to access for the computers room and systems management. The researchers attribute this result to the fact that the expert systems guarantee reading data and records, while focusing on the steps of change in the applications of the accounting systems. This increases the chance for controlling and authenticating the inputs.

3) The expert systems enhance the files security and protection in the Jordanian industrial companies by using developed and adequate programs to protect computers and software from viruses. The researchers attribute this result to the fact that the expert systems provide security and protection for the database by not allowing any users of information to access other users' data; even the user cannot access the personal part of database without following certain instructions.

4) There is an effect of the expert systems on enhancing the controls of system documentation, development and maintenance in the Jordanian industrial companies by creating a manual that indicates a specified description for documenting all programs and hardware that are used in the system. The researchers attribute this result to the fact that the expert systems are important in the field of artificial intelligence. Thus, expert systems have high potential to produce creative ideas and practical solutions for difficult and complicated issues. In addition, these systems are used to document the knowledge and human experience and also support making semi structured decisions processes and the like.

The study explains the importance of expert system and its role in general control system and its importance over the computerized accounting information systems, so the study decreasing the gap between the general controls and information system as an artificial intelligence by discovering the impact of expert systems on these controls over computerized AIS, and get beneficial of the intelligent systems qualitative characteristics in management's different actions and decisions.

The study provides the following recommendations;

1. Because of the importance of expert systems in decision making process and other processes, The Jordanian industrial companies management need to provide a great deal for these systems requirements and components and participating in dividing and employing those systems.

2. Training programs should be prepared for the employees of the Jordanian industrial companies to increase their awareness and perception of the uses of the expert systems. This will help to avoid mistakes that could happen while using these systems. This will also enhance the general regulatory controls in those companies.

3. The companies should form a common work groups between the heads of departments when generalizing the expert systems, information systems and any other systems, which involve the functional and informational integration between all of the information systems which will allow decreasing and preventing information redundancy and asymmetry.

4. The companies should work on removing constraints encountered in the work of the expert systems. Thus, this reinforces the regulatory controls and its importance in companies' operations.

Future studies should be conducted on expert systems in sectors other than the industrial sector, and examine its role in internal auditing and in improving the administrative procedures in companies through studding suitable mediating and moderating variables. 


\section{References}

1. Aboa, Y. P. J. D. (2014). Continuous Auditing: Technology Involved, available on: https://dc.etsu. edu/cgi/viewcontent.cgi?article $=1218 \&$ context=honors

2. Ahmad, A. A. B. (2019). The Moderating role of Internal Control on the Relationship between Accounting Information System and Detection of Fraud: The Case of the Jordanian Banks. Journal of Academic Research in Economics and Management Sciences, 8(1), 37-48.

3. Auditing Standards Executive Committee. (1974). Statement on Auditing Standards No. 3".The Effects of EDP on the Auditor's Study and Evaluation of Internal Control"(New York: AICPA, 6-9.

4. Al-Qumboz, A., Mohammed, N., \& Abu-Naser, S. S. (2019). Spinach Expert System: Diseases and Symptoms. International Journal of Academic Information Systems Research (IJAISR), 3(3), 16-22.

5. kh Al-Dalabeeh, A. E. R., \& Al-Zeaud, H. A. (2012). Accounting information systems and their role in the measurement and cost thrifting in public shareholding industrial companies in Jordan. International Journal of Business and Management, 7(12), 97.

6. Appiah, K. O., Amos, K. N. M., Bashiru, J., Drammeh, P. H., \& Tuffour, S. (2017). Corporate governance and records management in private and public hospitals in Ghana, Records Management Journal, 27(1), 42-56.

7. Bahrammirzaee, A. (2010). A comparative survey of artificial intelligence applications in finance: artificial neural networks, expert system and hybrid intelligent systems, Neural Computing and Applications, 19(8), 1165-1195.

8. Baldwin, A. A., Brown, C. E., \& Trinkle, B. S. (2006). Opportunities for artificial intelligence development in the accounting domain: the case for auditing. Intelligent Systems in Accounting, Finance \& Management: International Journal, 14(3), 77-86.

9. Barta, G. (2018). The increasing role of IT auditors in financial audit: risks and intelligent answers. Business, Management and Education, 16(1), 81-93.

10.Bawaneh, S. S. (2018). Securing Information Technology for Banks and Accounting Information Systems. International Journal of Applied Engineering Research, 13(6), 3291-3300.

11.Beard, D., \& Wen, H. J. (2007). Reducing the threat level for accounting information systems, CPA JOURNAL, 77(5), 34.

12.Braam, G., \& Peeters, R. (2018). Corporate sustainability performance and assurance on sustainability reports: Diffusion of accounting practices in the realm of sustainable development. Corporate Social Responsibility and Environmental Management, 25(2), 164-181.

13.Chan, D.Y., \& Vasarhelyi, M.A. (2011). Innovation and practice of continuous auditing. International Journal of Accounting Information Systems, 12(2), 152-160.

14.Chandrasekaran, B. (1986). Generic tasks in knowledge-based reasoning: High-level building blocks for expert system design. IEEE expert, 1(3), 23-30.

15.Cheng, Y., Tao, F., Xu, L., \& Zhao, D. (2018). Advanced manufacturing systems: supply-demand matching of manufacturing resource based on complex networks and Internet of Things. Enterprise Information Systems, 12(7), 780-797.

16.Devale, A. B. \& Kulkarni, R. V. (2012). A Review of Expert System in Information System Audit. (IJCSIT) International Journal of Computer Science and Information Technologies, 3(5), pp-pp 5172-5175.

17.El-dalabeeh, A. E. R. K. (2019). The Impact of Accounting Information Systems Development on Improving E-commerce in the Jordainian Public Shareholding Industrial Companies. Academy of Accounting and Financial Studies Journal, 23(2), 1-11.

18.El-Dalabeeh, A., \& Al-Shbiel, S. O. (2012). The role of computerized accounting information systems in reducing the costs of medical services at King Abdullah University Hospital. Interdisciplinary journal of contemporary research in business, 4(6), 893-900.

19.Flowerday, S., \& Von Solms, R. (2005). Continuous auditing: verifying information integrity and providing assurances for financial reports. Computer Fraud \& Security, 2005(7), 12-16.

20.Hall, J. A. (2011). Accounting information systems. Cengage Learning.7th edition, USA. Available on : http://site.iugaza.edu.ps/hmadi/files/2014/11/JAMES-AIS_unprotected.pdf

21. Hazratzadeh, S., \& Navimipour, N.J. (2016). Colleague recommender system in the expert cloud using features matrix. Kybernetes, 45(9), 1342-1357. 
22.Issa, H., Sun, T., \& Vasarhelyi, M. A. (2016). Research ideas for artificial intelligence in auditing: The formalization of audit and workforce supplementation. Journal of Emerging Technologies in Accounting, 13(2), 1-20.

23.Jawabreh, O. A., \& Alrabei, A. M. (2012). The impact of accounting information system in planning, controlling and decision-making processes in Jodhpur hotels. Asian Journal of Finance \& Accounting, 4(1), 173-188.

24.Kozhakhmet, K.T., Bortsova, G. K. \& Atymtayeva, L.B. (2012). Some Issues of Development of Intelligent System for Information Security Auditing. Proceedings of the World Congress on engineering, Vol II WCE, London, U.K.

25.Lee, D.-E., Lim, T.-K. and Arditi, D. (2011). An Expert System for Auditing Quality Management Systems in Construction. Computer-Aided Civil and Infrastructure Engineering, 26(8), 612-631.

26.Leigh, W., Modani, N., Purvis, R., \& Roberts, T. (2002). Stock market trading rule discovery using technical charting heuristics. Expert Systems with Applications, 23(2), 155-159.

27.Lutui, R., \& Ahokovi, T. A. (2018). The relevance of a good internal control system in a computerised accounting information system, available on: https://ro.ecu.edu.au/cgi/viewcontent.cgi? article $=1225 \&$ context $=$ ism

28.McDuffie, R. S., \& Smith, L. M. (2006). Impact of an audit reporting expert system on learning performance: a teaching note. Accounting Education: an international journal, 15(01), 89-102.

29.Mehrabad, M. S., \& Brojeny, M. F. (2007). The development of an expert system for effective selection and appointment of the jobs applicants in human resource management. Computers \& Industrial Engineering, 53(2), 306-312.

30.Moscove, S. A. (2001). E-business security and controls. The CPA journal, 71(11), 40.

31.Omoteso, K. (2012). The application of artificial Intelligence in auditing: Looking back to the future. Expert Systems with Applications, Elsevier Inc., (39), 8490-8495.

32.Prajogo, D. I. (2016). The strategic fit between innovation strategies and business environment in delivering business performance. International journal of production Economics, 171, 241-249.

33.Price, C., \& Price, C. J. (1999). Computer-based diagnostic systems (Vol. 156). Heidelberg: Springer.

34.Qin, X. S., Huang, G. H., Chakma, A., Nie, X. H., \& Lin, Q. G. (2008). A MCDM-based expert system for climate-change impact assessment and adaptation planning-A case study for the Georgia Basin, Canada. Expert Systems with Applications, 34(3), 2164-2179.

35.Romney, M. (2006). Accounting Information System. $10^{\text {th }}$ ed., Pearson Edition.

36.Simin, S. S., Malekian, F., Alizadehm, F. and Taheri, M. (2013). Investigate the Effect of Expert Systems Application on Management performance. Islamic Azad University, Iran.

37.Stantchev, V., Colomo-Palacios, R., Soto-Acosta, P., \& Misra, S. (2014). Learning management systems and cloud file hosting services: A study on students' acceptance. Computers in Human Behavior, 31, 612-619.

38.Thaker, S., \& Nagori, V. (2018). Analysis of Fuzzification Process in Fuzzy Expert System. Procedia computer science, 132, 1308-1316.

39.Widodo, A., \& Yang, B. S. (2007). Support vector machine in machine condition monitoring and fault diagnosis. Mechanical systems and signal processing, 21(6), 2560-2574.

40.Yang, D. C., \& Vasarhelyi, M. A. (1995). The Application Of Expert Systems In Accounting, Available on: http://citeseerx.ist.psu.edu/viewdoc/download?doi=10.1.1.542.6246\&rep=rep1\&type=pdf 